training be fully as competent, in 90 per cent. of illnesses, as the three-year trained nurse, and fit into the average household better. The high-salary demand is the natural outcome of the absurdly long training period as compared with the short service later. Possibly the selfishness is a fatigue reaction to be overcome by an eight-hour day. Finally, personality and conduct are the resultant of heredity and the training begun a decade before the training school gets her. The corrective of bad breeding, lack of adaptability, and unwillingness to serve in emergencies, lies in a broader education, with less routine menial work, better home environment, and more inspiring and stimulating contacts.

Phil.t King Brown, M.D., San Francisco.

\section{SUCCESSFUL HUMAN INOCULATION WITH PURE CULTURES OF PFEIFFER'S BACILLUS (B. INFLUENZAE)}

To the Editor:-Some years ago when working with hemophilic bacilli from various respiratory infections, especially pertussis, I had occasion to test the pathogenicity of these organisms in the human throat. The result of this experiment was briefly recorded at the time in an article published under a general title (The Bacteriology of Whooping Cough, J. Infect. Dis. 3:1, 1906), and for this reason might now be overlooked. Since the results were so striking, and in view of the importance of these bacilli in relation to the recent pandemic of influenza, I have been led, at the suggestion of several workers in this field, to record again the experiment under a more definite and pointed title.

The essential facts are these: Hemophilic bacilli were being found by me commonly in the throats and sputums of a number of infectious diseases, including pertussis, measles, varicella, bronchitis and many others, during interepidemic periods of influenza. They appeared all alike and had not at that time nor have they since been differentiated from the bacillus described by Pfeiffer ( $B$. influenzae) as the cause of the influenza pandemic of 1889-1890.

Since these organisms revealed only slight pathogenic powers for animals and did not produce characteristic lesions in them, it was decided to test the effect of the bacilli on the human being. A young man, healthy in every way, volunteered and agreed to submit to the inoculation of his throat with pure cultures of the bacilli. Careful preliminary cultural examination of his throat revealed no bacilli of this character. $\mathrm{He}$ had not had pertussis, and according to his own statement and that of his relatives, had not had any serious illness. It is probable that he had never had true influenza, but this could not be certainly determined.

Typical blood agar pure cultures, twenty-four hours old recently isolated from an uncomplicated case of pertussis were selected for the inoculation. They were washed off and suspended in salt solution, the growth from six tubes being used. I call special attention to this large dosage. The throat, tonsils and nasal mucosa were thoroughly smeared with this suspension, an ordinary throat swab being employed for this purpose. On the second day, almost forty-eight hours after the inoculation, the patient complained of a chilly sensation, a cold sweat, some headache and weakress. His temperature rose from normal (98.4 F. the day previous) to 100.2 F. The same evening it registered $100.1 \mathrm{~F}$. The next morning it was normal again, but rose during the day to $99.5 \mathrm{~F}$. The third day his temperature was practically normal and continued so from that time on. He complained somewhat of a headache and of feeling unwell, and on the second morning said he coughed a little. His throat, on examination when the first symptoms appeared, was slightly hyperemic; the next morning there was present a thick layer of mucus on the pharyngeal wall, and from this time on he coughed, or rather hacked up large quantities of a stringy, tenacious, slightly purulent mucus. This condition continued, becoming gradually less marked, but was still apparent at the end of four weeks. This ccugh was not spasmodic; it did not resemble pertussis. The leukocyte count on the second day was 9,200 . Clinically there was little resemblance to influenza.
Bacteriologic examination of the mucus from the throat, obtained on the first day of symptoms, revealed almost a pure culture of the influenza-like bacilli. They were present both in the throat and on the nasal mucosa in enormous numbers. Direct smears of the expectorated mucoid sputum showed practically no other organism. They were identical in every detail with the organism inoculated. Examinations of the throat were made every few days for four weeks, after which time the patient was not accessible. The number of influenza organisms present became gradually less, but at the end of that time they were still present in considerable numbers. There were no complications.

This experiment shows that when Pfeiffer's bacillus is placed in the throat in large numbers it may grow for a long time and cause definite symptoms. These symptoms, however, do not indicate any specific infection; and this, it seems to me, is quite in accord with the fact that these bacilli are found so often in the throats of persons suffering with almost any respiratory infection. The experiment further shows that these bacilli are at least not always harmless saprophytes, and at times are capable of causing reactions which, though not specific in character, might modify secondarily a primary infection.

David J. Davis, M.D., Chicago.

Professor of Pathology, University of Illinois College of Medicine.

\section{MUTUAL RECOGNITION OF MEDICAL DEGREES IN NORTH AND SOUTH AMERICA}

(Translation)

To the Editor:-I have received the third number of the Spanish Edition of THE Journal, and $I$ have been most favorably impressed with its contents. It furnishes a most complete review of medical science, and gives a clear insight into the fraternal spirit which pervades the medical profession throughout the world. The world-wide scope of your publication gives it a position of advantage over local journals, especially over those whose main purpose seems to be the advertising of certain products.

Could you not inaugurate a movement which would include South America, Central America and North America, with the object of bringing about mutual recognition of medical degrees in all North and South American countries? The time has come when the reasons which may have existed in the past for national control of medical degrees no longer obtain, in view of the restricted privileges to which the holder of such degrees is entitled.

I base my opinion on the following considerations:

1. Medical science is universal.

2. The studies that constitute a medical course are practically identical everywhere, and the slight variations do not alter the basic scientific principles.

3. Physicians from all the American republics have exercised their profession with marked success on the battlefields and in the hospitals of Europe-is, then, their competence limited to war times?

4. There is reciprocity between several republics of South America: Argentina, Uruguay, Paraguay, Bolivia, Peru and Ecuador. Why not extend reciprocity to the other republics?

5. Physicians are especially fitted to give the highest expression to the fraternal spirit because of the peculiar character of their profession and owing to the fact that the medical works which they study in common constitute strong natural bond.

6. The time is near when the medical profession throughout the world will be regarded by the various governments as an indispensable counselor. Why not let North and South America pave the way? Some common agreement must soon be reached with: regard to the air, the water and the land, since micro-organisms are transmitted by these mediums. Then again, the medical profession of Pan-America must be the exponent of great social reforms, especially those of a humanitarian nature.

7. If preventive medicine and intellectual and social reciprocity are to rest on a solid foundation, it is essential that 